\title{
POLÍTICAS CULTURAIS DO GOVERNO LULA
}

\author{
Antonio Albino Canelas Rubim \\ Universidade Federal da Bahia, Brasil
}

\begin{abstract}
Resumo: Para serem avaliadas, as gestões de Gilberto Gil (2003-2008) e Juca Ferreira (2008 em diante) no Ministério da Cultura do Brasil não devem ser comparadas apenas com a gestão Francisco Weffort (1995-2002). Um estudo rigoroso requer que elas sejam confrontadas com as três tristes tradições que marcam as políticas culturais nacionais: a ausência, o autoritarismo e a instabilidade. O trabalho analisa as políticas culturais desenvolvidas pelo Governo Luiz Inácio Lula da Silva com este foco.
\end{abstract}

Palavras-chave: Políticas Culturais no Brasil. Políticas Culturais. Gestão Gilberto Gil. Gestão Juca Ferreira. Governo Lula. Brasil contemporâneo.

\section{Fazer política é expandir sempre as fronteiras do possível. Fazer cultura é combater sempre nas fronteiras do impossível Jorge Furtado}

Uma avaliação rigorosa das políticas culturais desenvolvidas pelo presidente Lula e os ministros Gilberto Gil e Juca Ferreira exige, antes de tudo, uma revisão das tradições, que historicamente vêm sendo construídos pela trajetória das políticas culturais no Brasil e não apenas uma análise crítica do governo imediatamente anterior (Fernando Henrique Cardoso) e sua gestão da cultura (Francisco Weffort). Os desafios a serem enfrentados, por certo, emergiram em plenitude no longo governo FHC / Weffort, mas já tinham tristes tradições.

A bibliografia existente sobre políticas culturais no país (disponibilizada em www.cult.ufba.br), dispersa em muitas áreas disciplinares, ainda não contempla um estudo histórico sistemático sobre o tema. Em livro anterior, a construção de uma visão pelo menos panorâmica das políticas culturais foi esboçada (RUBIM, 2007). Ele serve de substrato e torna possível distinguir e tecer os eixos de análise deste texto. Além dele, existem duas tentativas de visão mais abrangente delineadas por Márcio de Souza (2000) e José Álvaro Moises (2001).

O itinerário das políticas culturais, não resta dúvida, produziu tristes tradições e, por conseguinte, enormes desafios. Estas tristes tradições podem ser emblematicamente sintetizadas em três palavras: ausências, autoritarismos e instabilidades. Cabe, em seqüência, fazer uma visitação a tais signos, que em razoável medida resumem a vida prejudicada, para lembrar Adorno, das políticas culturais da nação brasileira. 


\section{Ausências}

Figura antiga, ela está presente entre nós desde os tempos da colônia. Quais as políticas para o desenvolvimento da cultura que podiam conviver com o período colonial? $\mathrm{O}$ menosprezo e a perseguição das culturas indígenas e africanas; o bloqueio das culturas ocidentais, em especial aquelas na época progressistas, como a francesa, com: a proibição de instalação de imprensas, o controle da circulação de livros, e a inexistência de ensino superior e universidades. Todos estes aspectos são faces deste obscurantismo. Cabe lembrar que outros colonialismos - todos condenáveis - não acionaram tais medidas. Por exemplo, "entre 1538 y 1812 se crearon en todo el espacio colonial hispanoamericano treinta universidades" (BUCHBINDER, 2005, p.13).

A independência brasileira não alterou este panorama. O Estado continuou sendo pouco sensível à cultura. Ela era tratada como um privilégio, em uma sociedade de alta exclusão social, ou como um ornamento (COUTINHO, 2000). As pessoalizadas atitudes culturais de Dom Pedro II, a rigor, não podem ser pensadas como uma efetiva política para a cultura. Estimular a inauguração dos Institutos Históricos e Geográficos; assumir uma postura de mecenas com alguns criadores culturais e ser, ele mesmo, um criador bissexto (em fotografia) não configuram uma nova atitude do Estado brasileiro em relação à cultura, como supõem Márcio de Souza e José Álvaro Moisés.

A República também continuou a tradição de ausência do Império. As esporádicas ações na área de patrimônio não podem ser tomadas como uma nova atitude do Estado no campo cultural. Do mesmo modo, o momento privilegiado do desenvolvimento da cultura no Brasil, acontecido entre os anos "democráticos" de 1945 a 1964, não foi caracterizado por uma maior intervenção do Estado na área da cultura. O uso, em 1953, da expressão cultura para designar secundariamente um ministério, Educação e Cultura, e a criação do Instituto Superior de Estudos Brasileiros (ISEB), além de outras medidas menores, não sugerem nenhuma mutação essencial a esta persistente ausência de políticas culturais no Brasil.

A "Nova República” introduz uma nova modalidade de ausência com suas ambíguas investidas políticas culturais. Ela expande o Estado no registro da cultura, mas, ao mesmo tempo, introduz um mecanismo que solapa em grande medida uma atuação cultural mais consistente do Estado. A lei Sarney e as subseqüentes leis de incentivo à cultura, através da isenção fiscal, retiram o poder de decisão do Estado, ainda que o recurso econômico utilizado seja majoritariamente público, e colocam a deliberação em mãos da iniciativa privada. Nesta perversa modalidade de ausência, o Estado só está presente como fonte de financiamento. A política de cultura, naquilo que implica 
deliberações, escolhas e prioridades, é propriedade das empresas e suas gerências de marketing.

No governo FHC / Francisco Weffort esta nova modalidade de ausência tem seu ponto culminante. Agora a cultura é antes de tudo "um bom negócio", como assinala o mais conhecido manual editado pelo Ministério. Em um texto publicado no insuspeito livro intitulado A Era FHC, José Castello anota esta nova ausência do Estado. As leis de incentivo - agora designadas como Rouanet e do Audiovisual - assumem o lugar das políticas estatais (CASTELLO, 2002) e o mercado toma o papel do Estado.

Esta ausência no governo FHC paradoxalmente confirma a incapacidade da democracia no Brasil de atuar na área da cultura, detectada por um dos principais mentores do Ministério da Cultura naquele governo, o professor José Álvaro Moises. Ele havia reconhecido outra das tristes tradições brasileiras: a íntima e inusitada relação entre cultura e autoritarismo no país. Ele sentenciou:

“...o grande desafio da época contemporânea, na área da cultura, que é inverter a tendência histórica brasileira, segundo a qual os grandes avanços institucionais do setor fizeram-se em períodos autoritários” (Moises, 2001, p.46).

\section{Autoritarismos}

Primeira constatação: somente nos períodos autoritários o Brasil conheceu políticas culturais mais sistemáticas, nas quais o Estado assumiu um papel mais ativo e, por conseguinte, eclipsou a tradição de ausência. As ditaduras do Estado Novo (1937-1945) e dos militares (1964-1985), além da censura, repressão, medo, prisões, tortura, assassinatos, exílios inerentes a todo e qualquer regime autoritário, realizaram uma intervenção potente no campo cultural. Por certo tal atuação visava instrumentalizar a cultura; domesticar seu caráter crítico; submetê-la aos interesses autoritários; buscar sua utilização como fator de legitimação das ditaduras e, por vezes, como meio para a conformação de um imaginário de nacionalidade. Esta maior atenção significou, sem mais, enormes riscos para a cultura. Mas, de modo contraditório, esta "valorização" também acabou criando uma dinâmica cultural que trilhou as fronteiras possíveis das ditaduras, quando não extrapolou seus limites.

O governo Getúlio Vargas / Gustavo Capanema inaugurou mesmo a atuação sistemática do Estado na cultura. Dentre outros procedimentos, tem-se a criação de legislações para o cinema, a radiodifusão, as artes, as profissões culturais etc e a constituição de inúmeros organismos culturais, tais como: Superintendência de Educação Musical e Artística; Instituto Nacional de Cinema Educativo (1936); Serviço de Radiodifusão Educativa (1936); Serviço do Patrimônio Histórico e Artístico Nacional 
(1937); Serviço Nacional de Teatro (1937); Instituto Nacional do Livro (1937) e Conselho Nacional de Cultura (1938). Além disto, o "modernista" Gustavo Capanema, Ministro da Educação e Saúde (1934-1945), apesar de conservador, acolheu muitos intelectuais e artistas progressistas em seu ministério, em plena ditadura do Estado Novo, a começar pelo poeta Carlos Drummond de Andrade, seu chefe de gabinete, e outros como Oscar Niemeyer, Cândido Portinari etc. Pela primeira vez pode-se falar efetivamente em políticas culturais do Estado brasileiro. Simultaneamente, inauguramse as políticas culturais nacionais e a tradição de sua problemática conexão com o autoritarismo.

O golpe cívico-militar de 1964, mais uma vez, reafirmou esta triste tradição de relacionamento da cultura com o autoritarismo. Os militares não só reprimiram, censuraram, perseguiram, prenderam, assassinaram, exilaram a cultura, os intelectuais, os artistas, os cientistas e os criadores populares, mas, ao mesmo tempo, constituíram uma agenda de "realizações" nada desprezível para a (re)configuração do campo da cultura no Brasil. A ditadura investiu forte e deliberadamente no desenvolvimento das indústrias culturais no país, conformando toda infraestrutura sócio-tecnológica imprescindível à cultura midiatizada. A ditadura em sua fase inicial foi capaz de conviver, não sem tensões, com uma cultura nacional-popular de esquerda hegemônica em determinados setores sociais (SCHWARZ, 1978), enquanto desenvolvia e controlava ferreamente as indústrias culturais. Ou, por outras palavras, enquanto buscava realizar seu projeto de substituir a "hegemonia" do circuito escolaruniversitário - apesar de suas imensas limitações em um país marcado pela exclusão social - pelo protagonismo de um circuito conformado pelas indústrias culturais, rigidamente submetidas ao regime militar (RUBIM e RUBIM, 2004).

Além de induzir esta mutação brutal na conformação da cultura no Brasil, com todo o conjunto complexo de problemas que isto suscita, a Ditadura Militar, a exemplo do Estado Novo, também esboçou legislações culturais e criou inúmeros organismos no campo cultural. O Conselho Federal de Cultura (1966); o Instituto Nacional de Cinema (1966); a Empresa Brasileira de Filme - EMBRAFILME (1969); a Fundação Nacional das Artes - FUNARTE (1975); o Centro Nacional de Referência Cultural (1975); a RADIOBRÁS (1976); o Conselho Nacional de Cinema (1976) etc. Algumas destas instituições, a exemplo da FUNARTE, tiveram uma grande atuação em prol da cultura brasileira (BOTELHO, 2001). É sintomático desta tradição que o primeiro Plano Nacional de Cultura formulado no país tenha sido esboçado em 1975, em plena ditadura militar (MICELI, 1984). 
Mas a relação entre autoritarismo e cultura não se restringe aos regimes ditatoriais. Como muitos autores têm assinalado, em interpretações diferenciadas, o autoritarismo está impregnado na sociedade brasileira, dada a sua desigualdade social (FERNANDES, 1975; COUTINHO, 2000 e CHAUI, 2000). Este elitismo se expressa, em um plano macro-social, no desconhecimento, perseguição e aniquilamento de culturas e na exclusão cultural a que é submetida parte significativa da população. Ele está entranhado em quase todos os poros da sociedade brasileira. Por exemplo, nas visões de cultura subjacentes às políticas culturais empreendidas.

A trajetória e as orientações do Instituto do Patrimônio Histórico e Artístico Nacional (IPHAN), órgão fundado em 1937 no governo Vargas / Capanema, são emblemáticas nesta perspectiva. O IPHAN tem sido um dos organismos mais persistentes e relevantes das políticas culturais do Estado brasileiro, adquirindo inclusive um renome internacional. Durante uma parcela significativa de seu itinerário, ele privilegiou a cultura ocidental, branca, católica, barroca e monumental. Somente foram tombados e preservados: palácios, igrejas e fortalezas (MICELI, 2001 e GONÇALVES, 1996).

As culturas populares, indígena, afro-brasileira e mesmo midiática foram muito pouco contempladas pelas políticas culturais nacionais, quando elas existiam. Por certo, eram consideradas manifestações não dignas de serem reconhecidas e tratadas como cultura, quando não eram pura e simplesmente reprimidas e silenciadas. Nenhuma política e instituição mais consistentes foram implantadas para as culturas populares, apesar de terem existido algumas mobilizações, acontecidas no período democrático de 1945 a 1964, a exemplo da Campanha Nacional do Folclore e do Movimento de Cultura Popular, conformado pelos governos de Arraes em Recife e Pernambuco. Pelo contrário, tais manifestações foram reprimidas. A cultura indígena foi desconsiderada, quando não sistematicamente aniquilada. A cultura afro-brasileira, sempre perseguida, só começou a merecer algum respeito do Estado nacional, no período pós Ditadura Militar, com a criação da Fundação Palmares em 1988, resultado das pressões do movimento negro organizado e do clima criado pela redemocratização do país.

O rádio e a televisão foram sempre menosprezados pelo Ministério da Cultura, mesmo sendo os equipamentos culturais mais presentes no território brasileiro e tendo um vital papel cultural para a maioria da população brasileira, em especial, depois que passaram a se constituir como o circuito cultural hegemônico no país. A cultura midiática nunca foi considerada como algo digno da ação ministerial. O descompasso entre estas modalidades de cultura vivenciadas pela população brasileira - ainda que com todos os seus problemas de padronização e submissão à lógica mercantil das indústrias culturais - e o universo atendido pela intervenção do Ministério da Cultura, 
por certo, é um dos mais gritantes contrastes das políticas culturais do Estado brasileiro. Ele denota elitismo e autoritarismo.

A opção por uma concepção restrita de cultura, que engloba apenas as expressões mais reconhecidas pela elite, expressa com extrema fidelidade a visão autoritária e excludente da intervenção do Estado nacional no campo cultural, conformando a segunda de suas tristes tradições.

\section{Instabilidades}

A conjugação de ausência e autoritarismo produz instabilidades, a terceira triste tradição inscrita nas políticas culturais nacionais. Ela tem, de imediato, uma faceta institucional. Muitas das instituições culturais criadas têm forte instabilidade institucional derivada de um complexo conjunto de fatores: fragilidade; ausência de políticas mais persistentes; descontinuidades administrativas; desleixo; agressões de situações autoritárias etc. O governo Vargas cria instituições, mas destrói experiências políticas e culturais relevantes como a vivida por Mário de Andrade no Departamento de Cultura da Prefeitura de São Paulo (1935-1938). A ditadura militar fecha em 1964 o ISEB, os Centros Populares de Cultura da União Nacional dos Estudantes e o Movimento de Cultura Popular, onde aparece Paulo Freire. O afã neoliberal de Collor desmonta, como um bárbaro, quase todas as instituições culturais do país. Isto apenas para citar alguns momentos dramáticos.

Uma das poucas instituições nacionais que foi capaz de burlar a sina da instabilidade foi o IPHAN / SPHAN, organização emblemática da política cultural no país até o final dos anos 60 e início da década seguinte. Criado a partir de uma proposta encomendada por Gustavo Capanema a Mário de Andrade, mas não plenamente aceita (MICELI, 2001, p.360; CHAGAS, 2003 e FALCÃO, 1984, p.29), o SPHAN acolheu modernistas, a começar pelo seu quase eterno dirigente: Rodrigo de Melo Franco (1937 até sua morte nos anos 60). O Serviço, depois Instituto ou Secretaria, optou pela preservação do patrimônio de pedra e cal, de cultura branca, de estética barroca e teor monumental. Em geral: igrejas católicas, fortalezas e palácios do período colonial. Com isto, o IPHAN circunscreveu a sua área de atuação, diluiu possíveis polêmicas, desenvolveu sua competência técnica qualificada e profissionalizou seu pessoal. Tais atitudes, em conjunto com o "insulamento institucional", garantem a independência e a impressionante continuidade organizacional e administrativa da entidade e de seu dirigente (MICELI, 2001, p.362) e transformam o SPHAN em algo exemplar para as políticas culturais no Brasil e em muitos outros países. 
O setor de cultura esteve inscrito no Ministério de Educação e Saúde (1930) até passar a compor o novo Ministério de Educação e Cultura, em 1953. Foram precisos mais 32 anos para a independência e autonomia da cultura em um ministério específico (1985). Sua implantação foi deveras complicada. Com a pressão legítima dos intelectuais, artistas e secretários estaduais de cultura, muitos de governos de oposição à Ditadura Militar, a criação do ministério se tornou quase inevitável com o retorno da democracia em 1985. Entretanto, esta constatação não pode esquecer uma temática essencial, anotada por alguns estudiosos como Isaura Botelho: a existência ou não de maturidade institucional e dos agentes culturais para a criação do ministério.

A sua problemática implantação nos governos Sarney, Collor e Itamar é um dos exemplos mais contundentes desta tradição de instabilidade da área cultural. $\mathrm{O}$ Ministério da Cultura é criado em 1985; desmantelado por Collor e transformado em secretaria em 1990; novamente recriado em 1993 por Itamar Franco. A área cultural, além destas idas e vindas do ministério em seus primeiros anos, teve uns inacreditáveis dez dirigentes responsáveis pelos órgãos nacionais de cultura em nove anos (19851994): cinco ministros (José Aparecido, Aloísio Pimenta, Celso Furtado, Hugo Napoleão e novamente José Aparecido) nos cinco anos de Sarney (1985-1990); dois secretários (Ipojuca Pontes e Sérgio Paulo Rouanet) no período Collor (1990-1992) e três ministros (Antonio Houaiss, Jerônimo Moscardo, Luiz Roberto Nascimento de Silva) no governo Itamar Franco (1992-1995). A permanência média de menos de um dirigente por ano, com certeza, criou uma instabilidade institucional bastante grave, em especial para um organismo que estava em processo de instalação.

A radical diferença entre a instabilidade destes tumultuados anos iniciais e a estabilidade dos oito anos seguintes do presidente FHC e do ministro Francisco Weffort não conduziu a uma superação plena desta tradição de instabilidade. Por certo, o ministério não foi submetido ao tumulto institucional anterior, mas isto não significou um aumento correspondente da institucionalidade do Ministério da Cultura, pois este processo não depende apenas da estabilidade, mas exige uma gama complexa de outros procedimentos que não foram efetivados no longo governo FHC - Weffort.

Por certo, a destinação de apenas 0,14\% do orçamento da União para a cultura em 2002, último ano de FHC - Weffort, jamais pode ser tomado como um fator de fortalecimento institucional do ministério. Antes pelo contrário, indica o acentuado desprestigio da área cultural naquele governo. Aliás, a continuada situação de orçamentos precários - com poucas exceções históricas, como a fase inicial da FUNARTE - apresenta-se como outro componente nada desprezível da tradição de instabilidade da área nacional da cultura. Um orçamento digno é, sem dúvida, um 
indicador vital da importância política e institucional dada pelo governo federal ao Ministério da Cultura e um fator concreto de sua estabilidade.

Outras variáveis são fundamentais para a maior institucionalidade do ministério e, por conseguinte, para a superação da tradição de instabilidade. Dentre elas, podem ser lembradas: a quantidade e a localização dos seus equipamentos culturais, as dimensões quantitativa e qualitativa de seu corpo funcional, e a existência ou não de políticas públicas e/ou de Estado (e não apenas de governo) que permitam a continuidade das ações do ministério.

O itinerário institucional da cultura não tem sido pródigo em nenhuma destas variáveis. A criação do ministério em 1985 não implicou uma descentralização e nacionalização dos equipamentos e, por conseguinte, da atuação do órgão. Ele continuou sendo um ministério que opera de modo muito localizado e desigual. As tentativas de reverter esta situação foram sempre ocasionais e não resultaram em sua efetiva descentralização e nacionalização. O ministério gira em torno do Rio de Janeiro, principalmente, e de Brasília e São Paulo. A quase totalidade de seus órgãos e instalações encontra-se nestas regiões. A exceção é novamente o IPHAN, em especial, a partir do mandato de Aloísio Magalhães, que, em 1979 / 1980, criou representações regionais do IPHAN em varias regiões do país. Assim, existe deste sempre uma dificuldade institucional de uma presença nacional do ministério, o que torna sua atuação frágil e instável.

O corpo funcional tem sido componente que colabora para esta tradição de instabilidade. Com exceção, novamente, do IPHAN e em parte da FUNARTE, em alguns momentos, o corpo de funcionários do ministério tem sido precário, deficiente e não profissionalizado. Na sua trajetória inexistiram concursos para novas vagas, apesar do envelhecimento dos servidores e de fortes pressões para aposentadoria como ocorreu no governo Collor. Neste momento o quadro de funcionários foi reduzido de 4.371 para 2.796. Ou seja, 1.575 funcionários (PONTES, 1991, 27) a menos. O "esquecimento" de políticas de atualização e qualificação tem sido uma marca de praticamente todas as políticas culturais desenvolvidas pelos governos nacionais. Tal ausência chama a atenção. Ela torna-se evidente pela comparação da situação brasileira com a de outros países, de dimensões similares, como é o caso do México, onde a CONACULTA desenvolve um amplo e continuado programa de formação do pessoal da área de cultura. Esta, sem dúvida, é uma das ausências mais gritantes e graves das políticas brasileiras e um dos fatores mais eminentes da tradição de instabilidade da atuação do Estado nacional na cultura. 
Por fim, a instabilidade decorre da incapacidade dos governantes de desenvolver políticas de cultura que transcendam os limites dos seus governos e se tornem políticas de Estado, como acontece em outras áreas da administração federal, como por exemplo Educação, Saúde, Ciência e Tecnologia, e Relações Exteriores. Políticas, portanto, que exijam continuidade independente dos governos no poder, porque são alicerçadas em interesses estratégicos pactuados socialmente através de iniciativas de prazos, médios e longos.

A tradição autoritária das políticas culturais nacionais mais ativas tem impossibilitado, igualmente, que elas possam ser discutidas e negociadas com a sociedade civil, em especial com os setores interessados em cultura, e por conseqüência traduzidas em políticas públicas de cultura. Isto é, políticas que podem emanar do governo, mas que, submetidas ao crivo do debate crítico e da deliberação com a sociedade civil, se transformam em políticas públicas de cultura. Tais políticas, dado seu caráter democrático e pactuado, retêm mais possibilidade de transcender esta comprometedora tradição de instabilidade.

\section{Enfrentamentos}

Esboçada esta digressão histórica focada pelas noções-síntese das tradições, é possível agora analisar como o Governo Lula enfrenta ou não tais desafios. Outra vez, a ausência pode ser o ponto de partida. Na coletânea dos discursos "programáticos" pronunciados em seu primeiro ano de governo, Gilberto Gil privilegiou dois temas que batiam de frente com a tradição das ausências. Em uma perspectiva, enfatizou continuamente o papel ativo do Estado na formulação de políticas de cultura. Ele teceu uma poética relação entre políticas culturais e cultura. O artista ministro propôs que "formular políticas culturais é fazer cultura" (GIL, 2003, p.11). Em outra perspectiva, complementar à anterior, os discursos fizeram uma crítica contundente à gestão FHC / Weffort na medida em que ela significou a expressão maior da nova modalidade de ausência do Estado, com sua substituição e submissão ao mercado, através das leis de incentivo (GIL, 2003, p. 23, 49, 50, 51, 52 e 53).

O papel ativo do Estado se concretizou em inúmeras áreas culturais. Aliás, o próprio Gil disse que a marca de sua gestão seria a abrangência, contra todas as recomendações de políticos e profissionais de marketing político que viam nisto um perigo. Para além da abrangência de registros, o novo papel ativo do Estado se fez em conexão com a sociedade. Ele, várias vezes, afirmou que o público do ministério não era apenas os criadores e produtores culturais, mas a sociedade brasileira. Deste modo, o diálogo com a sociedade deu substancia ao caráter ativo, abrindo veredas para enfrentar o 
autoritarismo. Ou seja, o desafio de inaugurar políticas culturais em circunstâncias democráticas foi nitidamente colocado na agenda do ministério.

Outra das ênfases dos discursos programáticos encontra uma sintonia fina com a idéia força da luta contra o autoritarismo e o elitismo: a ampliação do conceito de cultura (GIL, 2003, p.10, 22, 44, 45). A insistência pela amplitude se traduz na opção por um conceito abrangente de cultura, dito "antropológico". A assimilação da noção larga permite que o ministério deixe de estar circunscrito à cultura culta (em geral: artes e patrimônio) e abra suas fronteiras para outras modalidades de culturas: populares; afro-brasileiras; indígenas; de gênero; de orientação sexual; das mídias; das redes informáticas; das periferias etc.

A abrangência, como já foi dito, torna-se uma característica da gestão Gil, bastante contraposta ao itinerário da área nacional de cultura, pois ela somente buscou interagir com tais modalidades em fases muito determinadas. Dentre estes momentos podem ser lembradas as iniciativas de Aloísio Magalhães (1985), as da FUNARTE (BOTELHO, 2001), e as do período Eduardo Portela, através das concepções de Pedro Demo (1982).

Em alguns casos, a atuação do Ministério da Cultura passa mesmo a ser inauguradora, a exemplo da atenção e do apoio às culturas indígenas (MINISTÉRIO DA CULTURA, 2006, 26). O estado nacional nunca havia se relacionado com os povos indígenas em uma perspectiva cultural. Toda a relação entre estado e comunidades indígenas acontecia através do Ministério da Justiça, com sua Fundação Nacional do Índio. Em outros casos, se não é inaugural, sem dúvida revela um diferencial de investimento em relação às situações anteriores. É o que acontece nas culturas populares (MINISTÉRIO DA CULTURA, 2005), de afirmação sexual, na cultura digital e mesmo na cultura midiática audiovisual. São exemplos força desta atuação: o deslocamento institucional da ANCINE para o Ministério da Cultura; a tentativa de transformar a ANCINE em ANCINAV; o projeto DOC-TV, que associa o ministério à rede pública de televisão para produzir documentários em todo o país; a luta pela Televisão Pública; o programa Revelando os Brasis, que apóia a produção audiovisual em cidades de até 20 mil habitantes; o edital para jogos eletrônicos; os apoios às paradas gay; os seminários nacionais de culturas populares etc.

A abertura conceitual e de atuação significa não só o abandono de uma visão elitista e discriminadora de cultura, mas representa um contraponto ao autoritarismo e a busca da democratização das políticas culturais. A intensa opção por construir políticas públicas, porque em debate e deliberação com a sociedade, emerge como outra marca das gestões Gil e Juca. Assim, proliferam os seminários, as câmaras setoriais, as 
conferências - inclusive culminando na Conferência Nacional de Cultura - e os debates sobre temas das políticas culturais. O desafio de construir políticas de cultura em um ambiente democrático não é enfrentado de qualquer modo, mas através do acionamento da sociedade civil e dos agentes culturais na conformação de políticas públicas e democráticas de cultura.

As políticas públicas dão substrato democrático para a viabilização de políticas de Estado, que transcendendo governos possam dar ao campo cultural políticas nacionais mais permanentes. Nesta perspectiva, os investimentos, ainda iniciais, do ministério na área da economia da cultura e da economia criativa e sua ação junto ao IBGE no sentido de produzir séries de informações culturais adquirem notável funcionalidade e já apresentam seus primeiros resultados (IBGE, 2006).

Mas dois outros movimentos assumem lugar central na construção de políticas de Estado no campo cultural: a implantação e desenvolvimento do Sistema Nacional de Cultura (SNC) e do Plano Nacional de Cultura (PNC).

A construção que vem sendo realizada pelo ministério, em parceria com estados, municípios e sociedade civil, de um Sistema Nacional de Cultura é vital para a consolidação de estruturas e de políticas, pactuadas e complementares, que viabilizem a existência e persistência de programas culturais de médios e longos prazos, logo não submetidas às intempéries conjunturais. Tal sistema deve estar associado e comportar outros (sub)sistemas que vêm se constituindo, como o Sistema Nacional de Museus (MINISTÉRIO DA CULTURA, 2006, 22).

A aprovação pelo Congresso Nacional (Emenda constitucional número 48/2005) e subseqüente elaboração do Plano Nacional de Cultura e sua aprovação pelo Congresso Nacional em 2010 surge como outro fator favorável à superação da tradição de instabilidade e descontinuidade que tem dilacerado a atuação estatal no campo da cultura. Enfim, a possibilidade de superação desta triste tradição depende em ampla medida da existência, articulação e sintonia fina entre SNC e o PNC.

A institucionalização do ministério se consolida com sua atuação cada vez mais nacional, através de inúmeros projetos, com destaque para os Pontos de Cultura, que já atingiram algo em torno de quatro mil em todo o país. A descentralização das atividades do ministério decorre também da reforma administrativa realizada logo no início da gestão, que buscou superar as áreas de sombreamento e dar maior operacionalidade ao ministério e seus órgãos vinculados (MEIRA, 2004); da expansão do IPHAN para a quase totalidade dos estados brasileiros, e da revitalização e ampliação das representações regionais do Ministério. 
A realização do "primeiro concurso público da história do ministério" desde sua inauguração em 1985 (MINISTÉRIO DA CULTURA, 2006, 18), sem dúvida, traz perspectivas alvissareiras para o fortalecimento institucional do ministério, através da incorporação de novos servidores, além da sinalização que propicia e da simbologia que aciona indicando uma atenção com a cultura.

Dois outros fatores têm essencial significado para a construção institucional do ministério. O primeiro é a ampliação dos recursos destinados à cultura através da renúncia fiscal e do orçamento do ministério (de 0,14\% em 2003 para algo em torno de $1,00 \%$ ), ainda que isto não tenha atendido plenamente à meta dos ministros Gilberto Gil e Juca Ferreira, de 1\% do orçamento nacional para a cultura. O segundo é a permanência no segundo mandato do presidente Lula da mesma equipe à frente do Ministério, ainda que com a substituição do ministro Gilberto Gil por Juca Ferreira, seu Secretário Executivo desde o início do Governo. Esta manutenção deve ser interpretada como compromisso com a continuidade das políticas empreendidas. A dimensão supranacional adquirida pelo Ministério igualmente tem contribuído para a busca de superação das tristes tradições detectadas neste texto: ausência, autoritarismo e instabilidade.

\section{Limitações e desafios}

Cabe agora analisar os desafios colocados por este novo patamar de políticas culturais nacionais no Brasil, depois de revisitadas as tristes tradições e seu enfrentamento pelas gestões dos ministros Gilberto Gil e Juca Ferreira. As diferentes análises, evocando múltiplos aspectos das políticas culturais empreendidas, apontam para o novo horizonte das políticas culturais nacionais no país. Elas agora existem de modo efetivo, habitam um ambiente democrático e contam com boas possibilidades de se tornarem mais permanentes. Ou seja, um novo e promissor patamar das políticas culturais nacionais foi alcançado no Brasil.

A envergadura deste novo patamar, no entanto, não está determinada, devido ao processo estar em curso, com múltiplas variáveis que podem afetar de modo contundente sua trajetória e avaliação. Por exemplo, caso os projetos pertinentes ao Ministério da Cultura que hoje tramitam no Congresso Nacional sejam aprovados em sua totalidade, viveremos no Brasil uma circunstância histórica radicalmente distinta para o desenvolvimento das políticas culturais nacionais. Poderíamos falar mesmo de um momento revolucionário e inaugurador de um cenário inédito de potencialidades. $\mathrm{Na}$ fronteira oposta, a não aprovação de muitas ou mesmo da totalidade destes instrumentos, que expressam e consolidam legalmente políticas, deprime imensamente 
o horizonte de possibilidades e bloqueia um salto verdadeiramente qualitativo e quantitativo das políticas culturais nacionais.

Não só as potencialidades futuras correm perigo com a não aprovação de algumas destas medidas. Em algumas situações, as tensões podem dilacerar mesmo políticas em processo. O risco de isto acontecer não é nada desprezível, dada a fragilidade do campo cultural, mesmo depois dos experimentos propiciados pelo Governo Lula.

O exemplo da política de financiamento da cultura torna-se emblemático por denunciar hoje esta tensão. Sem uma inversão radical na política de financiamento, as políticas de diversidade cultural e regional do Ministério são colocadas em xeque, porque o predomínio (gigantesco) das leis de incentivo não se apresenta como a modalidade adequada para garantir tais políticas. O conflito entre políticas implantadas e modos de financiamento é evidente. Ele tende a corroer e impedir o desenvolvimento de tais políticas, que são hoje a marca identificadora do Ministério. Recolocar as políticas de financiamento como subordinadas às políticas culturais desenvolvidas torna-se uma atitude imprescindível para a conformação de um novo patamar das políticas públicas de cultura no Brasil. Caso não aconteça esta reversão, isto irá comprometer de modo substantivo a redefinição do papel do estado com relação às políticas culturais, pois até hoje a modalidade majoritária de financiamento à cultura no país continua sendo a das leis de incentivo e, por conseguinte, o poder de decisão continua em mãos das empresas em detrimento do estado.

A redefinição rigorosa do papel do estado é outro desafio vital do momento contemporâneo. Urge a realização de debate democrático, amplo e qualificado para iluminar melhor a complexa atuação do estado hoje, inclusive no campo cultural, no Brasil e no mundo. Debate político que venha acompanhado pelo processo de construção de um estado radicalmente democrático. Nem o estado autoritário, nem o estado neoliberal dão conta da complexidade da circunstância cultural atual. O estado democrático deve aprimorar cada vez mais seus dispositivos de participação, a exemplo das conferências, colegiados e conselhos, e de construção, em conjunto com a sociedade, das políticas públicas, inclusive de cultura. O trabalho colaborativo entre estado e sociedade aparece como uma das alternativas mais consistentes de democratizar o estado, e de criar fronteiras nítidas e barreiras consistentes às investidas contemporâneas das empresas, em especial globais, que assumem um papel todo poderoso na atualidade e buscam insistentemente deprimir e capturar o estado.

Duas outras definições são igualmente urgentes. De um lado, é necessária uma melhor delimitação do campo de atuação do Ministério para dar consistência a sua ação e 
reflexão, aprimorando mesmo sua interação transversal com outras áreas sociais afins. Assim, torna-se imperiosa uma reflexão teórico-conceitual e ao mesmo tempo política acerca da noção e do campo de atuação do Ministério. A ampliação do conceito de cultura foi vital para superar o autoritarismo vigente na sociedade e nas políticas culturais no país, mas ele já se mostra insuficiente e problemático para o momento atual. Um debate, qualificado e democrático, sobre a temática impõe-se como vital para a consolidação da nova dinâmica de atuação do Ministério da Cultura.

De outro lado, outra dificuldade nada desprezível diz respeito ao tema dos criadores. O correto deslocamento do olhar do Ministério para a sociedade requer como complemento imprescindível a construção de uma política específica para os criadores, que defina com clareza, justiça e relevância o novo lugar a ser ocupado, em especial pelos artistas, intelectuais e cientistas, no cenário da cultura e principalmente das políticas culturais executadas. Não parece que isto tenha sido bem equacionado pelo Ministério, como fizeram crer as continuadas mudanças na direção da Fundação Nacional das Artes (FUNARTE) durante o Governo Lula. A construção colaborativa desta política, com envolvimento dos criadores, emerge como outro desafio vital para as políticas culturais nacionais do momento pós-Lula.

Esta questão está intrinsecamente associada ao tema da conformação da base social de apoio às políticas desenvolvidas pelo Ministério. No cenário anterior, os campos do patrimônio e das artes constituíam esta comunidade de interlocução e apoio. Na nova circunstância acontece um deslocamento relevante, pois a noção de cultura e a política cultural ampliadas requerem uma base social alargada para o Ministério. Em razoável medida, o Programa Cultura Viva, com sua capilaridade nacional, tornou possível, pelo menos em parte, a tessitura desta nova base de legitimação do Ministério, apesar dos problemas de gestão e de adequação a um estado ainda não democratizado o suficiente para interagir de modo adequado com estas novas comunidades culturais acolhidas pelo programa. Por certo, esta base de legitimação não pode prescindir de comunidades culturais profissionalizadas, mas esta maior abrangência torna-se imprescindível para estabelecer uma sintonia fina com esta nova cena. A crise atual do programa Cultura Viva emerge como muito preocupante não só porque atinge um dos programas de maior visibilidade da gestão Gil e Juca, inclusive replicado em outros países dado seu sucesso e caráter inovador, mas também porque coloca em xeque um programa emblemático em termos de dar amplitude a uma base social necessária a esta nova etapa de vida do Ministério. A incompreensão destes factos constitui uma atitude problemática. 
A implantação satisfatória do PNC, com prioridades e metas bem delineadas e possíveis, ainda que em patamares exigentes, configura outro desafio fundamental. $\mathrm{O}$ PNC inaugura no campo das políticas culturais públicas brasileiras um horizonte de planejamento e de articulação institucional e social bastante significativo. Mas o PNC exige para sua qualificada implantação que o SNC e o Projeto de Emenda Constitucional (PEC) 150 - que define percentuais orçamentários mínimos para a União, Estados e Municípios - sejam igualmente aprovados pelo Congresso Nacional e instalados como políticas de estado. Sem um reforço na institucionalidade cultural e sem mais recursos financeiros, passíveis de serem acionados pelos entes federativos de modo complementar, o PNC corre acentuados riscos de não passar de um belo documento. O dilema sempre renovado, infelizmente, do orçamento insuficiente e dos cortes orçamentários no campo da cultura surge como ameaça substantiva a uma maior estabilidade e ao amadurecimento das políticas na esfera da cultura.

Os temas da formação e qualificação em cultura e da própria organização do campo cultural também devem ser inscritos no panorama dos desafios contemporâneos das políticas culturais nacionais no Brasil. Eles implicam um reforço da institucionalidade cultural, requisito vital para a satisfatória resolução das políticas neste novo momento nacional. A implantação do PNC e do SNC exige profissionais de cultura mais qualificados e uma comunidade cultural mais organizada e ativa.

Além destas leis em andamento no Congresso Nacional, outras também têm lugar relevante no contexto contemporâneo, brasileiro e internacional. O projeto de lei dos direitos autorais, que atualiza a atrasada legislação brasileira na área, por exemplo, assume lugar de destaque. Em uma sociedade contemporânea, na qual a riqueza depende cada vez mais da produção do conhecimento, a propriedade intelectual e dos direitos autorais adquire um estatuto nada desprezível para o desenvolvimento econômico, social, ambiental, político e cultural.

Os desafios do novo cenário são enormes. Eles estão em sintonia com o patamar alcançado pela circunstância política e cultural. Resta saber se o Ministério da Cultura, a comunidade cultural, e a sociedade brasileira saberão enfrentá-los de modo democrático e consistente.

\section{Referências bibliográficas}


ABDANUR, Elizabeth França. Os "Ilustrados" e a política cultural em São Paulo. O Departamento de Cultura na Gestão Mário de Andrade (1935-1938). Campinas, UNICAMP (História), 1992 (dissertação de mestrado).

BADARÓ, Murilo. Gustavo Capanema. A revolução na cultura. Rio de Janeiro, Nova Fronteira, 2000.

BARBALHO, Alexandre. Relações entre Estado e cultura no Brasil. Ijuí, Editora UNIJUÍ, 1998.

BARBATO JR., Roberto. Missionários de uma utopia nacional-popular. Os intelectuais e o Departamento de Cultura de São Paulo. São Paulo, Annablume / Fapesp, 2004.

BARCELOS, Jalusa. CPC-UNE. Uma história de paixão e consciência. Rio de Janeiro, Nova Fronteira, 1994.

BASTOS, Mônica Rugai. O espelho da nação: a cultura como objeto de política no governo Fernando Henrique Cardoso. São Paulo, Faculdade de Filosofia e Ciências Humanas da Universidade de São Paulo, 2004 (Tese de doutoramento)

BERLINK, Manoel T. Centro Popular de Cultura da UNE. Campinas, Papirus, 1984.

BOTELHO, Isaura. Romance de formação: FUNARTE e política cultural 1976-1990. Rio de Janeiro, Casa de Rui Barbosa, 2001.

BOTELHO, Isaura. Dimensões da cultura e políticas públicas. In: São Paulo em Perspectiva. São Paulo, 15(2): 73-83, abril / junho de 2001.

BUCHBINDER, Pablo. Historia de las universidades argentinas. Buenos Aires, Editorial Sudamerica, 2005.

CASTELLO, José. Cultura. In: LAMOUNIER, Bolívar e FIGUEIREDO, Rubens (orgs.) A Era FHC: um balanço. São Paulo, Cultura, 2002, p. 627-656.

CHAGAS, Mário. O pai de Macunaíma e o patrimônio espiritual. In: ABREU, Regina e CHAGAS, Mário (orgs.). Memória e patrimônio: ensaios contemporâneos. Rio de Janeiro, FAPERJ / DP\&A / UNI-RIO, 2003, p. 95-108.

CHAUI, Marilena. Brasil. Mito fundador e sociedade autoritária. São Paulo, Fundação Perseu Abramo, 2000.

CHAUI, Marilena. O nacional e o popular na cultura brasileira. Seminários. São Paulo, Brasiliense, 1983. 
COUTINHO, Carlos Nelson. Cultura e sociedade na Brasil. Rio de Janeiro, DP\&A, 2000.

DEMO, Pedro. Dimensão cultural da política social. Recife, Massangana, 1982.

DÓRIA, Carlos Alberto. Os federais da cultura. São Paulo, Biruta, 2003.

FERNANDES, Florestan. A revolução burguesa no Brasil. Rio de Janeiro, Zahar, 1975.

FERREIRA, Juca. ANCINAV: omissão ou missão? In: Teoria e Debate. São Paulo, (60): 64-67, novembro /dezembro de 2004.

FUNDAÇÃO JOÃO PINHEIRO. A indústria cultural no quadro da economia brasileira. Brasília, MINC, 1987.

GIL, Gilberto. Discursos do Ministro da Cultura Gilberto Gil. Brasília, Ministério da Cultura, 2003.

GOMES, Ângela de Castro (org.). Capanema: o ministro e o ministério. Rio de Janeiro, Fundação Getúlio Vargas, 2000.

GONÇALVES, José Reginaldo Santos. A retórica da perda. Os discursos do patrimônio cultural no Brasil. Rio de Janeiro, Editora da UFRJ / IPHAN, 1996.

INSTITUTO BRASILEIRO DE GEOGRAFIA E ESTATÍSTICA. Sistema de informações e indicadores culturais 2003. Rio de Janeiro, IBGE, 2006.

LULA PRESIDENTE. Brasil: cultivar a memória, inventar o futuro. Programa Setorial de Cultura. Brasil, 2006.

MAGAlHÃES, Aloísio. E Triunfo? A questão dos bens culturais no Brasil. Rio de Janeiro / Brasília, Nova Fronteira / Fundação Nacional Pró-Memória, 1985.

MEIRA, Márcio. Uma política republicana. In: Teoria e Debate. São Paulo, (58): 60-65, maio /junho de 2004.

MICELI, Sérgio (org.) Estado e cultura no Brasil. São Paulo, Difel, 1984.

MICELI, Sérgio. Intelectuais à brasileira. São Paulo, Companhia das Letras, 2001.

MINISTÉRIO DA CULTURA. Cultura é um bom negócio. Brasília, MINC, 1995.

MINISTÉRIO DA CULTURA. Seminário Nacional de Políticas Públicas para as Culturas Populares. Brasília, MINC, 2005. 
MINISTÉRIO DA CULTURA. Programa cultural para o desenvolvimento do Brasil. Brasília, Ministério da Cultura, 2006.

MOISÉS, José Álvaro. Estrutura institucional do setor cultural no Brasil. In: MOISÉS, José Álvaro e outros. Cultura e democracia. Volume I. Rio de Janeiro, Edições Fundão Nacional de Cultura, 2001, p.13-55.

OLIVIERI, Cristiane Garcia. Cultura neoliberal. Leis de incentivo como política pública de cultura. São Paulo, Escrituras / Instituto Pensarte, 2004.

ORTIZ, Renato. Cultura brasileira e identidade nacional. São Paulo, Brasiliense, 1985.

ORTIZ, Renato. A moderna tradição brasileira. Cultura brasileira e indústria cultural. São Paulo, Brasiliense, 1989.

PARTIDO DOS TRABALHADORES. A imaginação a serviço do Brasil. São Paulo, PT, 2003.

PONTES, Ipojuca. Cultura e modernidade. Brasília, Secretaria de Cultura, 1991.

RAFFAINI, Patrícia Tavares. Esculpindo a cultura na forma Brasil: o Departamento de Cultura de São Paulo (1935-1938). São Paulo, Humanitas, 2001 (Dissertação de mestrado em História - Faculdade de Filosofia, Letras e Ciências Humanas da Universidade de São Paulo, 1999).

RAMÍREZ NIETO, Jorge. El discurso Vargas Capanema y la arquitectura moderna en Brasil. Bogotá, Universidad Nacional de Colômbia, 2000.

RUBIM, Antonio Albino Canelas. As políticas culturais e o governo Lula. São Paulo, Editora da Fundação Perseu Abramo, 2011.

RUBIM, Antonio Albino Canelas (org.). Políticas culturais no Governo Lula. Salvador, EDUFBA, 2010.

RUBIM, Antonio Albino Canelas. Políticas culturais no Brasil: itinerários e atualidade. In: BOLAÑO, César; GOLIN, Cida e BRITTOS, Valério (orgs.). Economia da arte e da cultura. São Paulo, Observatório do Itaú Cultural, 2010, p.51-71.

RUBIM, Antonio Albino Canelas. Discussão sobre o Plano Nacional de Cultura. In: Teoria e Debate. São Paulo, (81):48-51, março-abril de 2009.

RUBIM, Antonio Albino Canelas e BARBALHO, Alexandre (orgs). Políticas culturais no Brasil. Salvador: EDUFBA, 2007. 
RUBIM, Antonio Albino Canelas. Políticas culturais entre o possível e o impossível. Texto apresentado no II Encontro de Estudos Multidisciplinares em Cultura. Salvador, 2006.

RUBIM, Antonio Albino Canelas e RUBIM, Lindinalva. Televisão e políticas culturais no Brasil. In: Revista USP. São Paulo, (61): 16-28, março / abril / maio de 2004.

SARCOVAS, Yacoff. O incentivo fiscal no Brasil. In: Teoria \& Debate. São Paulo, (62)58-62, abril / maio de 2005.

SARNEY, José. Incentivo à cultura e sociedade industrial. In: JELÍN, Elizabth e outros. Cultura e desenvolvimento. Rio de Janeiro, Fundo Nacional de Cultura, 2000, p. 27-44.

SCHELLING, Vivian. A presença do povo na cultura brasileira. Ensaio sobre o pensamento de Mário de Andrade e Paulo Freire. Campinas, Editora da UNICAMP, 1991.

SCHWARZ, Roberto. Cultura e política: 1964 - 1969. In: O pai de família e outros estudos. Rio de Janeiro, Paz e Terra, 1978, p.61-92.

SOUZA, Márcio. Fascínio e repulsa. Estado, cultura e sociedade no Brasil. Rio de Janeiro, Edições Fundo Nacional de Cultura, 2000 (Cadernos de Nosso Tempo número 02).

TOLEDO, Caio Navarro de. ISEB: fábrica de ideologias. São Paulo, Ática, 1977.

VELLOSO, Mônica Pimenta. Os intelectuais e a política cultural do Estado Novo. Rio de Janeiro, Centro de Pesquisa e Documentação de História Contemporânea do Brasil Fundação Getúlio Vargas, 1987.

WILLIAMS, Daryle. Gustavo Capanema. Ministro da Cultura. In: GOMES, Ângela de Castro (org.) Capanema: o ministro e seu ministério. Rio de Janeiro, Editora FGV, 2000, p.251-269.

Albino Rubim é Professor Titular do Instituto de Humanidades, Artes e Ciências Professor Milton Santos da Universidade Federal da Bahia. Docente do Programa Multidisciplinar de Pós-Graduação em Cultura e Sociedade. Pesquisador do Centro de Estudos Multidisciplinares em Cultura. Pesquisador I-A do CNPq. Atual Secretário de Cultura do Estado da Bahia. 